THEORIA ET HISTORIA SCIENTIARUM, VOL. XI

Ed. Nicolaus Copernicus University 2014

First published online 31.01.2015

http://dx.doi.org/10.12775/ths-2014-011

\title{
Sławomir Wacewicz
}

Center for Language Evolution Studies (CLES); Department of English

Nicolaus Copernicus University

wacewicz@umk.pl

\section{The shades of social. A discussion of The social origins of language, ed. Daniel Dor, Chris Knight and Jerome Lewis}

\begin{abstract}
Turning to the social dimension has been an influential trend in recent language evolution literature, as documented by e.g. Dunbar et al. (ed. 2014), ScottPhillips (2014), or Pina and Gontier (ed. 2014). The social origins of language, edited by Daniel Dor, Chris Knight and Jerome Lewis, is of special interest, because rather than just being part of this trend, it aims to redefine the current discourse in language origins research, making it inclusive and "society first". Collectively, the twenty four chapters of this volume make a powerful statement for a broad, incorporative, "everything counts" approach to language evolution. By demonstrating the relevance to language evolution research of a wide variety of social, cultural and cognitive factors, The social origins of language is potentially - and hopefully - a game changing contribution to this field of study.
\end{abstract}

Keywords: language evolution, evolution of language, language origins, social communication, social signaling, cultural evolution

\section{Introduction}

Contemporary evolutionary linguistics, or more broadly research into language evolution, can be seen as growing out of the philosophical tradition of big "origins" questions and into pursuing these questions with more down-to-earth, empirical methodologies of cognitive science. For quite some time, however, the weight of interest has been shifting from the cognitive to 
the social. The achievement of the cognitive turn was to take the spotlight away from, for example, the anatomical prerequisites for speech to questions regarding the "language faculty" - symbolization, mimesis, theory of mind and other cognitive underpinnings of language. But now, the "social turn" is taking it one step further: not only by putting the ontogeny and phylogeny of those cognitive capacities in a social context, but also by pointing to mechanisms and phenomena irreducible to individual cognition.

Language evolution literature has been addressing and even directly referencing "the social" for some time now ${ }^{1}$, but recent - and very recent - publications representing this trend are much more numerous. Examples from 2014 include Dunbar et al. (ed 2014), Scott-Phillips (2014), as well as The evolution of social communication in primates (ed. Pina and Gontier 2014), which is reviewed in the present volume (Dębska 2014). However, The social origins of language, edited by Daniel Dor, Chris Knight and Jerome Lewis, holds a special place in this mix, aspiring - rightly, in my view - to the role of an important programmatic statement. Dor et al.'s aim is to redefine the current discourse in language evolution: from "genes first" to "society first".

\section{What's "the social"?}

A good place to start is the classic Wittgensteinian insight that all language is necessarily social - at least in a certain minimal way. The famous "beetlein-the-box" example (Wittgenstein 1987 [1953]: 100) serves as a reminder that language by nature is always public. Since linguistic labels are arbitrary and conventional, their meanings are not fixed by individual fiat but must instead arise dynamically through repeated communicative interaction. Private language is an illusion, and a solipsistic agent cannot be linguistic the social group comes first.

But what does "social" mean in "The social origins of language"? This question is tackled head on in a couple of chapters, such as those by Sverker Johansson (2014), and N. J. Enfield and Jack Sidnell (2014), but the answer turns out to be tricky and elusive. The twenty four chapters present, in fact, a very diverse range of perspectives that are not easily united by any obvious single common ground. Here, Wittgenstein is helpful again. The reason

An early example is The Evolutionary Emergence of Language: Social Function and the Origins of Linguistic Form, ed. Knight et al. (2000), a volume growing out of the second edition of the field's main conference, EVOLANG. 
the volume does not lose its integrity - just like with the Wittgensteinian "games" - is that it contains several distinct but converging senses of the "social", forming threads that interweave throughout the publication to keep it together.

One way to construe the social origins is as the kind of selection pressures leading to the evolutionary emergence and development of language. This could mean the thesis that language evolved for communication, in the footsteps of Steven Pinker and Paul Bloom (1990) - and pace e.g. Noam Chomsky and his camp, who suggest at times that language could have evolved for cognition, or even for no reason in particular ${ }^{2}$. While still influential, the latter remains a minority view in the language evolution circles, and the former is shared by a broad majority - a stance acknowledged (e.g. in the chapter by Johansson [2014]), but not actively defended in the volume.

In a related sense, the selection pressures in question need not be involved in shaping language directly, but rather in forming the necessary preconditions, or preadaptations, for language (c.f. e.g. Donald 1999; Hurford 1999). In this sense, the social thesis would mean that the "prime movers" of the hominin cognitive development were social rather than, for example, ecological. This point is much more nuanced, as it depends on what cognitive capacities one takes as prerequisites for language emergence, and it enjoys less universal support. Notably, Derek Bickerton (e.g. 1998; Calvin and Bickerton 2000) observes that complex sociality is characteristic of many primate species who live in large groups and exercise Machiavellian intelligence to navigate intricate political webs. Even monkeys can possess an impressively advanced social calculus allowing them e.g. to process transitive rank (Seyfarth and Cheney 2001), and a correlation between the group size and neocortex volume is well attested in primates (Dunbar 1993), yet none of this seems to turn their communicative systems into anything resembling language. To Bickerton (1998), the selective "prime movers" behind the evolution of human-like cognition must have come from ecological factors, especially the challenges of extractive foraging on the savannah.

\footnotetext{
2 "We know very little about what happens when 1010 neurons are crammed into something the size of a basketball, with further conditions imposed by the specific manner in which this system developed over time. It would be a serious error to suppose that all properties, or the interesting properties of the structures that evolved, can be 'explained' in terms of 'natural selection'." (Chomsky 1975:59), quoted by Jackendoff (2002: 234).
} 
Bickerton's work is referenced surprisingly sparingly throughout the volume, and his position is not confronted directly. Rather, the book implies a different conceptualization of cognitive evolution and of the nature of language. The human difference does not necessarily begin with greater generalized "processing power" that would form a foundation for language superimposed on top of it. Rather, the chapters in Dor et al.'s collection stress how the phylogeny of the internal cognitive capacities for language is, from the very beginning, immersed in a rich external social context and dependent on an intricate external social-cultural scaffolding.

\section{Social signals and cooperation}

A unifying theme central to the entire volume is the question of the honesty of linguistic signals - and its cooperative underpinnings. Research on cooperation has now become a major industry, spanning several disciplines, from intercultural developmental psychology to neuroeconomics. Cooperation is approached from various directions, from phenomenological to behaviouristic, and using diverse methodologies, from theoretical work (e.g. West et al. 2011), to experimentation (usually in the social dilemma games paradigm, e.g. Ledyard 1995), to computational and mathematical modelling (e.g. Nowak 2006).

In language evolution, the cooperative nature of human communication is of absolutely critical importance. As is often emphasized, humans share valuable information with biologically unrelated individuals and do so without incurring any costs (at least, any obvious costs) to back up the honesty of the message. This cooperative dimension is generally recognized in the language evolution circles as a key theoretical challenge, or a "central puzzle" (Fitch 2010), and so it is in the volume ${ }^{3}$. "The major transition, all of us agree, must have been the establishment within social groups of unprecedentedly co-operative, trusting relationships", state the editors (Dor et al. 2014: 12). The different authors approach this issue from different angles - trust, honesty, reputation, reciprocity, morality, pro-sociality, normativity, collaboration, altruism - but almost every chapter at least acknowledges this consensus. Many also work out its implications in more detail.

3 The full quote from Fitch (2010): "The cooperative sharing of information thus remains a central puzzle in language evolution", is echoed by Zlatev (2014: 249). 


\subsection{From vocal grooming to reverse dominance}

In two chapters aimed at theoretical syntheses, Chris Knight (2014) and Jordan Zlatev (2014) address the origins of distinctly human, cooperative sociality. Zlatev singles out four "major players" - Dunbar's (1996) vocal grooming account, Deacon's (1997) social contract account, Tomasello's (2008) shared intentionality/prosociality account, and Hrdy's (2009) alloparenting account - and examines them by comparing their answers to five questions: "Why us and not others?", "How?", "When?", "What kind of social groups?", and "Development?" Zlatev's overall conclusion is that all four are not only possible to reconcile with multilevel selection, but in fact highly compatible with multilevel selection mechanisms, including group selection.

Dunbar's account grows out of one of the most intriguing and important discoveries in language evolution research - the correlation between primate non-visual neocortex volume and group size (also length of the juvenile period: see Joffe 1997) - but Zlatev rightly notes its shortcomings: vocal grooming by itself does not have to lead to humanlike sociality or communication (see also e.g. Johansson 2005: 213). One should also observe that vocal grooming, unlike real grooming, is a cheap signal, so its communicative functioning presupposes rather than explains the existence of a cooperative context (see Power 1998).

Zlatev is relatively sympathetic to Deacon's "marriage/male provisioning" account, which envisages the males as "forced" to cooperate with the females to provision unusually altricial hominin infants, this cooperation being governed by symbolically mediated social norms. That said, Zlatev's highlight on the group-selection elements, though not unfounded, seems to be overstated: "male provisioning" is defensible in terms of individual reproductive success of offspring benefitting from greater parental investment ${ }^{4}$.

Tomasello's shared intentionality/prosociality account is very well established in the language evolution literature, but Hrdy's alloparenting proposal - convergent with Tomasello's in many respects - has recently received growing recognition. Hrdy's central insight lies in observing that non-human primates can in fact exhibit highly cooperative social patterns: in providing collective, group-level care to offspring. Where humans are special is in combining this pattern of cooperative breeding specific to (some)

4 It should also be remembered that Deacon himself considers "male provisioning" merely as a scenario, additional rather than central to his now classic 1997 book. 
monkeys with advanced cognition characteristic of the Great Apes. Zlatev observes that although Hrdy's proposal fails to provide candidate selection pressures behind this unique combination, it identifies the preexisting platform of trust on which intersubjectivity and prosociality can grow; this makes her account not only compatible, but also complementary with that of Tomasello.

In his review chapter, Chris Knight (2014) agrees that symbols require trust, but he offers an insight that goes deeper. Following the argument developed in Camilla Power's (2014a) chapter, Knight emphasizes that normally in animal communication a small 'efficacy' cost of transmitting the information must be accompanied by a large 'strategic' cost of proving that the information is true (see e.g. Maynard Smith and Harper 2003). This cannot work for symbolic communication. Language, Knight argues, is a lie not only in the sense of potentially conveying false propositional content, but much more immediately, in each word being a fake: a fiction not certified for its veracity by a large strategic cost. If each symbol had to be proven true, token by token, it would be next to impossible to transcend one-symbol utterances and achieve combinatorial meaning. Hence, social agreement has a much more fundamental role to play in symbolic communication than purely establishing the sign's reference: first of all, it mandates believing in the sign. Symbolic communication requires taking symbols as true without demanding proof, that is suspending the disbelief which is the default condition in communication by nonhumans.

Central to Knight's standpoint is the notion of reproductive levelling. In social groups with appreciable reproductive skew, males have incentives to vie for dominance over the rest of the group, as this ensures greater reproductive success. But increasing size of hominin groups and increasing Machiavellian intelligence of the groups' members create more opportunities for subordinates to form powerful coalitions that could successfully subvert the position of the leader and undermine his (Darwinian) payoff. With successful counter-dominance strategies in place, competing for status only poorly translates into fitness advantages, which leads to groups being more egalitarian and more cooperative. Thus, symbols depend on cooperation, which in turn depends on egalitarian social patterns (not accidentally so characteristic of present-day hunter-gatherers). Knight provides an overview of several theoretical positions on each of those issues, and as the last chronologically, first - step, he sees the likely origins of egalitarianism in female coalitions. Here he mentions the accounts by Sarah Hrdy and Kristen Hawkes, but sides with the Female Cosmetic Coalitions (FCC) model. 


\subsection{Female Cosmetic Coalitions}

The author of the FCC model, Camilla Power, has contributed two texts to the volume, Chapters 4 and 15. The first one (Power 2014a) serves to set the stage: working from rigorously Darwinian assumptions about cooperation and signalling, she delves deeper into the special status of language, which functions by combining elements that are individually unsubstantiated "fakes". She also views group size - with resulting increased encephalisation and Machiavellian intelligence - as promoting counterdominance and reverse dominance strategies, which in turn lead to egalitarian social patterns. What is more, as competition for social intelligence favours greater investment in large-brained but altricial offspring, hominin females face intense pressures for mobilizing male provisioning and blocking male philandering.

Those are the foundations of the Female Cosmetic Coalitions (FCC) model, which Power presents in the later chapter (2014b). Its key component is menstruation - given concealed ovulation of the human female, the only visible sign of her reproductive status and imminent fertility (also one of the most central themes in present-day hunter-gatherer cultures). This may provoke conflict both between males - for sexual access - and females - for maintaining the investment of males, who may be tempted to desert their currently non-cycling partners to pair with the cycling females. On Power's FCC account, hominin females would have taken counter-measures by forming a coalition dedicated to collectively "jamming" the menstrual signal. They would have applied red cosmetics to their bodies, which would have masked their status and (even more importantly) signalled solidarity, forcing the males to seek sexual favours on the terms of the female coalition rather than their own. Cosmetic adornments, originally proto-ritual displays indexically referring to menstrual blood, would then have evolved into more elaborate symbolic rituals standing for female collective denial of sex; such rituals would be the original source of a group's repertoire of shared fictions.

The chapter by Ian Watts (2014) fleshes out this scenario with archaeological detail. Most evidence in favour of the FCC model has to do

\footnotetext{
"Signal evolution theory is the main body of theory applied to animal communication. So it is axiomatic that any scientific study of the evolution of language adopts this theoretical approach as starting point. To argue that the evolution of language is a special case to which signalling theory does not apply, we have to explain why not, within that theory's terms... We are not systematically monitoring for lies or liars. Indeed, language is in a sense built from components which are 'lies'-figures of speech whose 'truth' emerges only on a higher combinatorial level.” (Power 2014a: 50)
} 
with the use of red ochre, arguably the oldest archaeological trace of human activity that can be linked to symbolism of any kind ${ }^{6}$. Watts points to several facts, such as the kind of ochre used or correlations with encephalisation: the blood-red types of ochre were preferred to other colours, regular ochre use appears to co-occur with the last brain growth spurt in the Middle Stone Age, and finally, in Europe ochre use seems to follow a pattern of being less intense in the periods where ecological conditions produced birth seasonality (which would have reduced opportunities for male philandering, so that female coalitions would have had less demand for cosmetic rituals).

Watts' review of the evidence is admirably detailed and informative, but it also remains a sobering reminder of the limits of evidential power of the archaeological and fossil records, which can provide only most general grounding to the more advanced human origin models, such as the FCC. Inferences, when not disappointingly cautious, quickly become far-fetched: there is very little that fossil and archaeological record can legitimately tell us on the exact shape of Middle Stone Age ritual practices or social norms ${ }^{7}$. A good example of fallible reasoning is when Watts takes the postulated increase in brain size in the MSA to mean that modern language was not yet present at that time (contra what Dediu and Levinson [2014] have to say in their chapter). But why would language have put a stop to pressures for greater brainpower? This runs counter to the logic of authors such as Dor and Jablonka (2014), whereby culture, fuelled by increasingly effective symbolic communication, installs a feedback loop working to promote, not suppress, encephalisation.

Overall, the FCC is a complex model with many merits, such as accounting for the deep symbolic meaning of menstruation in hunter-gatherer societies,

6 A number of more ancient artefacts exist, including the recently reported engraved fossil shell dating back to about 500000 years ago (Joordens et al. 2014), whose interpretation, however, is much more controversial.

"There seem to have been significant obstacles to establishing a form of social organization that allowed some individuals to remain at a home base, indefinitely maintaining captured wildfire. Speculatively, these may have concerned an absence of mechanisms of punishment and reward to enforce cooperation between strangers, a prerequisite of 'institutional facts'." (Watts 2014: 215)

"Intriguingly, cut-marks on bone are more abundant and randomly oriented than in later Levantine contexts, suggesting that more individuals were involved, with little or no formal apportioning of meat (Stiner et al. 2009). This might be read as another indication of an absence or weak development of institutional facts." (Watts 2014: 215)

"The Wonderwerk pigments strongly suggest collective ritual dating back to 300 500 kya, with fire-lit 'song-and-dance' performances, the dancers glowing red and glittering." (Watts 2014: 217) 
and emphasizing the role of costly ritual in establishing social norms. That said, the repeated assertions of testability are overstated. The predictions it generates fit empirical data in ways that are appealing, but post-factum and vulnerable to confirmation bias; also, as mentioned above, archaeological data by their nature allow for only loose fit. The FCC remains an interesting contender, but one must remember that each step of this elaborate and multistep scenario needs to be treated as somewhat speculative.

\subsection{Why talk? The concept of risk-free killing}

Yet another perspective on the topic of trust and evolutionary stability of communication comes from Jean-Louis Dessalles (2014). He formulates this problem with rare succinctness: "If information has any value, it is in the interest of no one to give it for free. And if information has no value, why are there ears ready to listen to it?" (Dessalles 2014: 284). Here, Dessalles' principal interest lies in the "talker" rather than the "listener". While most theorizing focuses on the receiver's risks of being manipulated, Dessalles, admirably, asks us to consider the reverse question: what benefits does the sender derive from producing the message, given that consistent deception is not an option if communication is to be evolutionarily stable? In other words, why talk?

Dessalles points to the basic facts of human ethology, citing Geoffrey Miller's (2000) observation that where we compete is to speak rather than to listen ${ }^{8}$. Humans find talking inherently gratifying, which suggests it must have had adaptive value but does not tell us its exact nature. To Dessalles, the Darwinian answer is that using language is competitive signaling. Speakers want to show off, and they accomplish this by making their conversational turns relevant and imbuing them with highly desirable qualities: unexpected information, emotional content, and logical consistency. Even if the information conveyed is trivial rather than important (as is commonly the case in conversation), the speaker whose contributions meet the above criteria demonstrates cognitive characteristics which would make him a valued ally in the human EEA (Environment of Evolutionary Adaptedness).

To explain this last point, Dessalles turns the reader's attention to the phenomenon of risk-free killing. The main technological innovation in early hominins were stone tools, and one consequence of being able to

8 Fitch (2010) proposes a term derived from German, Mitteilungsbedürfnis, to capture the human urge to share information and emotions with others. 
use a stone tool effectively is being able to use it as a weapon. Assassination becomes an option. Unarmed, killing a competitor requires having enough strength and social support to overcome not just the opponent but also any individuals that might come to his rescue; even then the encounter may prove risky and costly. Weapons change this dramatically, as almost everyone becomes capable of dealing a lethal blow to a sleeping rival. The only protection, Dessalles notes, is having vigilant allies - and vigilance is best advertised in precisely those conversational contributions that are relevant and logical, and have unexpected content and emotional impact.

In my opinion, the concept of risk-free killing is the stronger part of Dessalles' scenario, and potentially a key idea in hominin evolution. Weapons, and the decreased costs of killing dominant individuals that came with them, would have had two related consequences, both very important. Firstly, social hierarchies would have depended even less on physical power and even more on social skills, which would have added fuel to the arms race of Machiavellian intelligence (with all the consequences to brain size, neonate altriciality, and group organization for infant provisioning). Secondly, the possibility of (almost) everyone to have in check (almost) everyone else would have constituted a powerful drive for social levelling. Those two points deserve closer attention from scholars whose models prioritise the social brain as well as counter-dominance and reverse dominance. Dessalles' account, in turn, would be more complete if he factored in the possible pressures from inter-group conflict: killing a member of one's own to replace him in hierarchy pays off immediately, but has an equally immediate cost of making the group more vulnerable to attacks from rival bands, resulting in its physical as well as genetic obliteration.

\section{Culture}

The role of culture in language emergence could be seen as another common thread, even though it may be better understood as not one but two distinct insights. Firstly, we have the cumulative potential of the cultural mechanisms of invention and innovation, most successfully captured in the ratchet effect analogy (e.g. Tomasello 1999). Innovation in a group would normally be lost after each generation, but cultural transmission acts as a pawl preventing the reset. By culturally inheriting the innovation, the new generation no longer has to start from scratch, and rather than devoting their lifetimes to reinventing the state of the art, they can "pick it up from there" and devote those lifetimes to advancing it further on. 
Secondly, we have the phenomenon of gene-culture co-evolution, first introduced into language evolution by Terrence Deacon, whose work is widely acknowledged throughout the volume. Deacon (1997) illustrated his case with the example of the human adaptation for post-weaning lactose tolerance, evolved along the Baldwinian lines. With culturally invented and transmitted technology of milk processing, such as fermenting or making cheese, milk would slowly become available as a food source to human adults in certain populations; this would increase their reliance on milk and dairy and result in a selection pressure for inborn lactose tolerance, leading to an even greater dependence on milk products and thus stimulating further technological progress in a gene-culture positive feedback loop.

Daniel Dor and Eva Jablonka (2014) offer an analogy of their own: the latent skill of echolocation. In humans it manifests itself to an appreciable degree only under rare circumstances, yet in a fantastic but at least conceptually possible scenario, in an isolated population of blind people this skill could be useful enough to make a difference. Not only could we expect Darwinian selection for it, but also that the development of this skill in ontogeny would be encouraged, and that technology and culture would be gradually redefined and "built around it", to assist and promote it on the one hand and exploit it on the other; all this would culminate in increasing natural selection to close the positive feedback loop. Likewise, language evolution is "phenotype-first", fuelled by developmental plasticity that is magnified by cultural-technological progress.

The step further that Dor and Jablonka want us to take, and the novelty of their proposal, is that the phenotype in "phenotype-first" is cultural rather than individual. The way language is different from lactose tolerance or echolocation is that it inevitably transcends a single person. It is no use for a lone individual - language necessarily means interaction between several minds, implying not just individual, but collective creativity. By its own nature, language involves group-level innovation. Each communication act unavoidably taps the advantages of brainstorming, leading to gains that exceed the sum of individual contributions: "group genius" over "lone genius". Collaborative innovation drives fast change in communicative technology, which can then be recursively applied to itself: as tools may be used to make better tools, emerging language becomes a means of promoting even more trust, collaboration and creativity.

Several other texts in the volume look into the role of cultural transmission, to a various extent. For example, Enfield (2014) looks into cultural epidemiology, specifically aiming at a more principled account of transmission biases (roughly equivalent to selection pressures 
in biological evolution). He puts forward a model of a four-stage cycle of cultural transmission: exposure (of an individual to the cultural "meme") - representation (encoding the "meme" in the memory) - reproduction (when the individual retrieves and uses the "meme") - material (the physical properties of the external representation); each stage involves a set of characteristic transmission biases. Enfield emphasizes the role of iterated practice in language, which goes beyond the standard iterated learning approach by closing up on the enchronic timescale: "the timescale of moves and countermoves in sequences of human interaction" (2014: 327).

\section{What is language?}

"Your theory of language evolution depends on your theory of language", says Ray Jackendoff (2010). The debate between the proponents of the narrow delineation of what can legitimately be called language and the advocates of a broader, integrative view (Hauser et al. 2002, Pinker and Jackendoff 2005; see also Wacewicz 2012, and Wacewicz and Żywiczyński, this volume) has been alive for more than a decade, and it continues to shape the controversies in the field. It may well be that the most important contribution of The social origins of language is not arguing for anything social per se, but rather making a consistent, convincing and powerful statement about the "broad" nature of language, and as a result championing the need for an all-inclusive perspective on its study. The introductory chapter, remarkable for its apt phrasing of many points, puts it eloquently:

With the rise of a multitude of new sub-disciplines, specialized journals, and conferences, and with the gradual decline of the Chomskian paradigm as a unifying framework, more and more of what we learn about language remains confined to specialized professional circles. However, to understand the origin of language requires a move in the opposite direction - a large-scale, collective interdisciplinary effort at theoretical synthesis. The detective-like analysis of circumstantial evidence knows no disciplinary borders. Everything counts. (Dor et al. 2014: 1-2)

...a very wide spectrum of entangled conditions is requiredcultural, social, political, cognitive, and emotional. In other words, language is an internal component of a much wider continuum: social intercourse and culture in distinctively human form. This, then, is why the problem is so difficult: to explain language, we 
seem to need nothing short of 'a theory of everything'- everything distinctive about human consciousness, life, and culture taken as a whole. (Dor et al. 2014: 12)

Language is not just a biological adaptation. The conceptualization of the language faculty only in terms of the organism's genetic make-up is incomplete, and Chris Sinha (2014) explains why by usefully analogizing language to animal artefactual niches, such as the bower in bowerbirds. As products of behavioral instructions largely coded in the organisms' genes, artefacts are organisms' creations - but the reverse is also true. Animals such as bowerbirds, beavers or termites are profoundly affected by their artefacts, which literally form the animals' niches, indispensable for their daily functioning, survival and reproduction, and equally heritable as genes. This analogy argues against taking biological and cultural evolution separately, and for treating the evolving entities as biocultural complexes: "phenogenotypes".

Another of the volume's excellent analogies is found in Charles Whitehead's (2014) chapter, who - building on the insights of Émile Durkheim and Chris Knight - notes that “.... any attempt to explain language as an isolated trait is akin to explaining the emergence of the credit card without considering the preconditions on which credit cards dependincluding commerce, money, banking, the digital computer, and the means to detect and punish fraud" (Whitehead 2014: 157). Accordingly, approaches that focus selectively on the formal combinatorial properties of the human language faculty can be compared to studying the structural and material properties of the plastic plate. This is not to question their validity or usefulness; problems begin when such a narrow approach is claimed to exhaust the scope of what is interesting or possible to know about language and its origins (cf. Wacewicz and Żywiczyński, this volume).

And what is interesting about language clearly cannot be narrowly limited to grammar or, for example, vocally transmitted information. In his chapter, Adam Kendon (2014) argues compellingly that extra-oral visible bodily action - communicative movements of the hand and arm, but also a variety of other signals such as movements of the trunk or head, or facial action - is an integral, essential and inalienable component of language?

9 "Extra-oral visible bodily action, in short, is deployed by speakers in ways that serve a great diversity of semantic functions but which yet, if done while the person is speaking, are so closely co-ordinated with this activity that it is to be understood as an integrated component of it." (Kendon 2014: 68) 
Extra-oral visible bodily actions, rather than being random "supplements [or] add-ons" to vocal signals, are patterned (rule governed), semantic (individually meaningful or related to the meanings expressed vocally), and very deeply integrated with speech. As a result, we should treat speech and the various visible expression systems as an ensemble, and "[a]ny theory of the evolutionary origins of language needs to take [extra-oral visible bodily action] into account" $(2014: 71)^{10}$.

Kendon calls our attention to ways in which human linguistic activity is not only multimodal, but also depends extensively on semiotic means other than symbolic signs. Jerome Lewis (2014) does the same in discussing multimodal communication in the Central African BaYaka Pygmy groups, modern hunter-gatherer representatives of the most ancient genetic lineages of humankind. Their daily communicative practices consist in versatile drawing on a variety of means of expression, from words, to reenactment, to different forms of music (themselves forming a continuum with speaking), to sonic mimesis: mimicked sounds that can be used flexibly in conversation to substitute conventional lexical labels. Lewis highlights how different this is from the default assumptions about the nature of language, especially those that present-day Western researchers, with their lifetime immersion in the written word, unwittingly bring to the study of language origins:

Mbendjele and other Pygmy groups' multi-modal communicative strategies targeting different audiences remind us of the environmentally embedded context of language use likely to have dominated in the past. BaYaka seek to speak as many 'languages' (djoki) as they can. Their speech is incorporative, open, encompassing, and inclusive. It is a skilful multi-modal deployment of a range of capacities inherent to human bodies that serve to establish relationships with as many creatures as possible. By contrast, most language users today think of languages as conceptually fixed to a distinctive vocabulary, grammar, and speech style, facilitating interaction between members of a particular human group, and as being political by being selective, exclusive, and oppositional. (Lewis 2014: 85)

10 Some may find it surprising that Kendon does not support any of the "gesture first" theories of language origins (e.g. Corballis 2002); but this is precisely for the reason just described - emphasis on the visual rather than vocal modality would face the same problem with explaining the deep integration between the modalities. 


\section{The language mosaic}

Overall, the twenty four chapters give us a broad, complex, and multifaceted vision of language evolution: what Hurford (2003) calls mosaic evolution or what Knight (personal communication) calls jigsaw evolution, as opposed to the magic ingredient $X$ evolution scenarios which seek to reduce language origins to a single crucial component. Again, this inclusive position is something that Dor, Knight and Lewis take special effort to emphasize: "On one point, we are all agreed: languages began evolving as a consequence not of one social factor but multiple interacting ones. This, then, is our overall thesis" (2014: 4). As the editors say, "everything counts", including "shared childcare, the control of fire and cooking, projectile weapons, big game hunting, increasingly equal power relations between the sexes, emotional bonding through music, dance and other forms of ritual - and, as a consequence of increased trust within relatively stable coalitions, steadily increasing chances for cultural innovations to be preserved and transmitted to future generations." (2014: 4)

It is impossible to do justice here to all twenty four texts in the volume. In the chapters not discussed above, Sverker Johansson (2014) looks into accessible sources of evidence in which to ground a language origins theory; Nick Enfield and Jack Sidnell (2014) demonstrate that one such source may be Conversation Analysis; Daniel Dor (2014) develops the view of language as a communication technology (introduced in the chapter co-authored with Jablonka); Simeone Pika (2014) reviews a wealth of information on visual communication in apes, with emphasis on chimpanzee gestures; Zanna Clay and Klaus Zuberbühler (2014), in contrast, focus on ape vocalisations, warning against writing them off as uninteresting emotional reactions; Dediu and Levinson (2014) overview a broad range of archaeological, paleoanthropological and linguistic evidence, all consistent with modern language being present as early as 500000 years ago; Emily Wyman (2014) is interested in language as a tool for doing things, and in the social prerequisites for enabling such performativity; this is related to Ehud Lamm's (2014) interest in normativity as such a precondition, but also something that grows together with language in a co-evolutionary dynamics; in another coevolutionary account, Simona Ginsburg and Eva Jablonka (2014) look into the power of lexical labels as cognitive enhancers, presenting word-based episodic recall as a crucial cognitive novelty; Chris Knight and Jerome Lewis (2014) build on their previous chapters, working towards a scenario of language origins from vocal mimesis; and Luc Steels' (2014) aim is to pull 
down what he sees as a number of false dichotomies: between synchrony and diachrony, nature and culture, competence and performance, processing and describing, and formalism and functionalism.

Because of the richness of the collection, there are a number of quite fundamental recurrent threads which I could not address: for example, the role of ritual (Knight, Lahm, Lewis, Power, Watts, Whitehead), the role of play and pretend-play (Dor, Ginsburg and Jablonka, Power, Whitehead, Wyman), and the idea of language as a medium for creating nonphysical but binding reality of Durkheimian institutional facts (Knight, Power, Watts, Wyman).

Collectively, the twenty four chapters deliver a clear message: no single discipline or research trend "owns" the field of language evolution. There is room there for conversation analysis, cultural anthropology/ethnography, gesture studies, robotics, and so on. Just as cooperation in hominid groups must have been a crucial prerequisite and a central piece in the puzzle of language emergence, cooperation across disciplinary borders will be a crucial prerequisite for solving it.

\section{References}

Bickerton, D. (1998). Catastrophic evolution: the case for a single step from protolanguage to full human language. In J.R. Hurford, M. Studdert-Kennedy and C. Knight (eds.). Approaches to the Evolution of Language. Cambridge: Cambridge University Press.

Calvin, W. H., Bickerton, D. (2000). Lingua ex Machina: Reconciling Darwin and Chomsky with the human brain. Cambridge, MA: MIT Press.

Clay, Z., Zuberbühler, K. (2014). Vocal communication and social awareness in chimpanzees and bonobos. In Dor et al. (eds.), 141-156.

Corballis, M. C. (2002). From hand to mouth: The origins of language. Princeton, NJ: Princeton University Press.

Deacon, T.W. (1997). The Symbolic Species: The Co-evolution of Language and the Brain. New York: Norton.

Dębska, A. (2014). Pointing in the right direction. A discussion of The Evolution of Social Communication in Primates, (eds.), M. Pina and N. Gontier. Theoria et Historia Scientiarum 11.

Dediu, D., Levinson, S. (2014). The time frame of the emergence of modern language and its implications. In Dor et al. (eds.), 184-195.

Dessalles, J. (2014). Why talk? In Dor et al. (eds.), 284-296.

Donald, M. (1999). Preconditions for the evolution of protolanguages. In M. C. Corballis and S. E. Lea (Ed.), The descent of mind: psychological 
perspectives on hominid evolution (pp. 138-154). Oxford: Oxford University Press.

Dor, D. (2014). The instruction of imagination: language and its evolution as a communication technology. In Dor et al. (eds.), 105-125.

Dor, D., Jablonka, E. (2014). Why we need to move from gene-culture co-evolution to culturally driven co-evolution. In Dor et al. (eds.), 15-30.

Dor, D., Knight, C., Lewis, J. (2014). Introduction: a social perspective on how language began. In Dor et al. (eds.), 1-14.

Dor, D., Knight, C., Lewis, J. (eds.). (2014). The social origins of language. Oxford: Oxford University Press.

Dunbar, R. I. M. (1993). Coevolution of neocortical size, group size and language in humans. Behavioral and Brain Sciences 16.4: 681-735.

Dunbar, R.I.M. (1996). Grooming, Gossip and the Evolution of Language. London: Faber and Faber.

Dunbar, R. I. M., Gamble, C., Gowlett, J. A. J. (ed.) (2014). Lucy to Language: The Benchmark Papers. Oxford: Oxford University Press.

Enfield, N. (2014). Transmission biases in the cultural evolution of language: towards an explanatory framework. In Dor et al. (eds.), 325-335.

Enfield, N., Sidnell, J. (2014).Language presupposes an enchronic infrastructure for social interaction. In Dor et al. (eds.), 92-104.

Fitch, W.T. (2010). The Evolution of Language. Cambridge: Cambridge University Press.

Ginsburg, S., Jablonka, E. (2014). Memory, imagination, and the evolution of modern language. In Dor et al. (eds.), 317-324.

Hauser, M., Chomsky, N. and Fitch T. (2002). The Faculty of Language: What. Is It, Who Has It, and How Did It Evolve? Science 298, 1569-1579.

Hrdy, S.B. (2009). Mothers and Others: The Evolutionary Origins of Mutual Understanding. Cambridge, MA: Belknap Press of Harvard.

Hurford, J.R. (1999). The evolution of language and languages. In R.I.M. Dunbar, Chris Knight and Camilla Power [eds.]. The Evolution of Culture. Edinburgh: Edinburgh University Press.

Hurford, J. (2003) The Language Mosaic and its Evolution. In M.H. Christiansen and S. Kirby, editors, Language Evolution: The States of the Art. Oxford University Press.

Jackendoff, R. 2002. Foundations of Language. Brain, Meaning, Grammar, Evolution. New York: Oxford University Press.

Jackendoff, R. (2010). Your theory of language evolution depends on your theory of language. The Evolution of Human Language: Biolinguistic Perspectives, 63-72.

Joffe, T. H. (1997). Social pressures have selected for an extended juvenile period in primates. Journal of Human Evolution 32: 593-605.

Johansson, S. (2005). Origins of Language: Constraints on hypotheses. Amsterdam: John Benjamins. 
Johansson, S. (2014). How can a social theory of language evolution be grounded in evidence? In Dor et al. (eds.), 56-64.

Joordens J.C., d'Errico F., Wesselingh F.P., Munro S., de V., Wallinga J., Ankjaergaard C., Reimann T., Wijbrans J.R., Kuiper K.F., Mucher H.J., Coqueugniot H., Prie V., Joosten I., van O., Schulp A.S., Panuel M., van, Lustenhouwer W., Reijmer J.J., Roebroeks W. (2014). "Homo erectus at Trinil on Java used shells for tool production and engraving." Nature. doi: 10.1038/nature13962.

Kendon. A. (2014). The 'poly-modalic' nature of utterances and its relevance for inquiring into language origins. In Dor et al. (eds.), 67-76.

Knight, C. (2014). Language and symbolic culture: an outcome of hunter-gatherer reverse dominance. In Dor et al. (eds.), 228-246.

Knight, C., Lewis, J. (2014). Vocal deception, laughter, and the linguistic significance of reverse dominance. In Dor et al. (eds.), 297-314.

Knight, C., Studdert-Kennedy, M., Hurford, J. R. (eds.). (2000). The Evolutionary Emergence of Language: Social function and the origins of linguistic form. Cambridge: Cambridge University Press.

Lamm, E. (2014). Forever united: the co-evolution of language and normativity. In Dor et al. (eds.), 267-283.

Ledyard, J. O. (1995). Public goods: a survey of experimental research. In J. H. Kagel and A. E. Roth (eds.), The handbook of experimental economics (pp. 111-194). Princeton: Princeton University Press.

Lewis, J. (2014). BaYaka Pygmy multi-modal and mimetic communication traditions. In Dor et al. (eds.), 77-91.

Maynard Smith, J., Harper, D. (2003). Animal Signals. Oxford: Oxford University Press.

Miller, G.F. (2000). The Mating Mind. New York: Doubleday.

Nowak, M. A. 2006. Five Rules for the Evolution of Cooperation. Science 314: $1560-1563$.

Pika, S. (2014). Chimpanzee grooming gestures and sounds: what might they tell us about how language evolved? In Dor et al. (eds.), 129-140.

Pina, M. Gontier, N. (eds.). (2014). The Evolution of Social Communication in Primates. A Multidisciplinary Approach. Cham: Springer.

Pinker, S., Bloom, P. (1990). Natural language and natural selection. Behavioral and Brain Sciences 13, 707-784.

Pinker, S., Jackendoff, R. (2005). The faculty of language: what's special about it?. Cognition 95.2, 201-236.

Power, C. (1998). Old wives' tales: the gossip hypothesis and the reliability of cheap signals. In J. R. Hurford, M. Studdert-Kennedy, and C. Knight (eds.), Approaches to the Evolution of Language, pp. 111-129. Cambridge: Cambridge University Press.

Power, C. (2014a). Signal evolution and the social brain. In Dor et al. (eds.), 47-55.

Power, C. (2014b). The evolution of ritual as a process of sexual selection. In Dor et al. (eds.), 196-207. 
Scott-Phillips, T. C. (2014). Speaking Our Minds: Why human communication is different, and how language evolved to make it special. Palgrave MacMillan Seyfarth, R.M. and Cheney, D.L. (2001). Cognitive strategies and the representation of social relations by monkeys. In Evolutionary Psychology and Motivation, Nebraska Symposium on Motivation, (Ed. by J. French, A. Kamil and D. Leger), Vol. 47, pp. 145-177. Lincoln, NE: U. of Nebraska Press.

Sinha, C. (2014). Niche construction and semiosis: biocultural and social dynamics. In Dor et al. (eds.), 31-46.

Steels, L. (2014). Breaking down false barriers to understanding. In Dor et al. (eds.), 336-349.

Tomasello, M. (1999). The Human Adaptation for Culture. Annual Review of Anthropology 28, 509-529.

Tomasello, M. (2008). The Origins of Human Communication, Cambridge, MA: MIT Press

Wacewicz, S. (2012). The narrow faculty of language: What is it, who has it, and how is it defined?. Theoria et Historia Scientiarum 9, 217-229.

Wacewicz, S., Żywiczyński, P. (2014). From the narrow to the broad. Multiple perspectives on language evolution. Theoria et Historia Scientiarum 11.

Watts, I. (2014). The red thread: pigment use and the evolution of collective ritual. In Dor et al. (eds.), 208-227.

West, S. A., C. El Mouden, A. Gardner. (2011). Sixteen common misconceptions about the evolution of cooperation in humans. Evolution and Human Behavior $32.4,231-262$.

Whitehead, C. (2014). Why humans and not apes: the social preconditions for the emergence of language. In Dor et al. (eds.), 157-170.

Wittgenstein, L. (1987) [1953] \{1953\}. Philosophical Investigations. Trans. G. Elisabeth M. Anscombe. Third edition. Oxford: Basil Blackwell \{Philosophische Untersuchungen.\}

Wyman, E. (2014). Language and collective fiction: from children's pretence to social institutions. In Dor et al. (eds.), 171-183.

Zlatev, J. (2014). The co-evolution of human intersubjectivity, morality, and language. In Dor et al. (eds.), 249-266. 